\title{
AISTHESIS EN EL REALISMO CRÍTICO DE LA CIUDAD Y LOS PERROS DE MARIO VARGAS LLOSA
}

\author{
José Morales Saravia \\ Universidad de Würzburg \\ Jose.Morales-Saravia@uni-wuerzburg.de
}

RESUMEN / ABSTRACT

Lo nuevo de la "nueva novela hispanoamericana", que La ciudad y los perros (1962) de Mario Vargas Llosa representa, se halla en el re-trabajo de las categorías suministradas por la tradición realista bajo premisas que buscan despertar en el lector vivencias directas de lo feo. Este artículo analiza ambas estéticas implicadas en ello: aquella que construye lo feo en toda su amplitud y aquella del efecto que hace vivenciar lo feo directamente por el lector.

Palabras clave: realismo, boom, estética, feísmo, efecto.

The new aspect of the "nueva novela hispanoamericana", represented by Vargas Llosa's 1962 The Time of Hero, lies in the rework of categories from the realistic tradition under premises that seek to awaken in readers direct experiences of ugliness. This article analyses the two aesthetics involved in this process: one that constructs a vast fiction world of ugliness (Karl Rosenkranz's Ästhetik des Hässlichen), and another that enables readers to experience ugliness directly (Wirkungsästhetik).

KEY WORDS: realism, boom novel, aesthetics, ugliness, effect.

\section{INTRODUCCIÓN}

La historia de la recepción inmediata de la novela La ciudad y los perros ha sido contada varias veces. El joven Vargas Llosa presenta este texto al premio 
"Biblioteca Breve", que la nueva casa editorial barcelonesa Seix Barral convoca en 1962, y lo gana. Con ello, el joven novelista no solo salta a la notoriedad internacional -la novela se traduce inmediatamente a varios idiomas- sino que inaugura ese fenómeno que a partir de entonces pasará a la historia literaria con el nombre de "boom" o de "nueva narrativa latinoamericana".

Basta revisar hoy en día la recepción inmediata de La ciudad y los perros en artículos y reseñas de esos años (véase la bibliografía al final) para comprobar el impacto que significó esta novela en el espacio cultural hispanoamericano. No se trata aquí solo del escándalo que provocó en el Perú y que llevó a que se quemaran los mil ejemplares de la edición peruana en el patio del Colegio Leoncio $\mathrm{Prado}^{2}$, sino de los patrones de lectura que la novela imponía con su tema -sí, el tema era para entonces escandaloso por lo que tenía de denuncia- pero sobre todo con su tratamiento de la materia. Para citar solo un ejemplo, el escritor cubano Ambrosio Fornet escribía, en su reseña de 1964, que se había acercado a la novela como lo hacen los lectores-escritores, es decir, con una mirada maliciosa que va a buscar las limitaciones del texto o a hacer la lista de sus objeciones y que esta novela, sin embargo, lo había desarmado totalmente, convirtiéndolo "de golpe en puro lector" (Fornet 129). A continuación, Fornet se ocupaba allí de las técnicas y procedimientos que Vargas Llosa había empleado, subrayaba el tratamiento diverso y diferenciado, pero unitario, de la materia encaminado a descubrir "los vicios de un sistema y la hipocresía de quienes lo sostienen" (Fornet 132) y concluía con una afirmación que dividía las aguas en un antes y un ahora:

Ha pasado para la novela latinoamericana la época de las imitaciones y de la asimilación apresurada de atmósferas extrañas; ha pasado también

${ }^{1}$ Es cierto que Carlos Fuentes ya había publicado para esas fechas La región más transparente (1958) y que Julio Cortázar -junto con Fuentes y García Márquez, el otro escritor de este fenómeno literario- tenía publicadas varias colecciones de cuentos. Ese año de 1962 es, sin embargo, - o mejor- el año siguiente de 1963, en que aparece la novela que nos ocupa y se publica también Rayuela, el que fungirá como fecha convencional de una nueva época literaria.

${ }^{2}$ Vargas Llosa ha escrito en su artículo "El país de las mil caras" de 1983, p. 236, lo siguiente: "El libro tuvo un llamativo recibimiento. Mil ejemplares fueron quemados ceremonialmente en el patio del Colegio y varios generales lo atacaron con dureza. Uno de ellos dijo que el libro había sido escrito por 'una mente degenerada', y, otro, más imaginativo, que sin duda era una novela pagada por el Ecuador para desprestigiar al Ejército peruano. El libro tuvo éxito pero yo me quedé siempre con la duda de si era por sus méritos o por el escándalo"... 
la época ingenua de la buena voluntad que hace mala literatura. Entre los jóvenes, Vargas Llosa ha dado el salto" (Fornet 132).

¿Pero cómo hay que interpretar este salto? ¿A qué se refiere en realidad Fornet? Él hacía un recuento de las acciones de la novela y mencionaba que se había retomado el viejo tema de la violencia que ahora se lo localizaba en el corazón de la ciudad y entre buenos muchachos que roban, se engañan, se humillan y finalmente asesinan. El salto que Vargas Llosa había dado tenía que ver, empero, con la forma cómo se hacía vivenciable para el lector esa violencia. Esto es lo que Fornet expresaba cuando escribía: "Kafka afirmaba, al hablar de la angustia, que no conocía sus leyes internas, sino solo la presión de sus dedos en la garganta" (Fornet 129). El salto residía, precisamente, en que el tratamiento riguroso y diferenciado enfrentaba al lector directamente con esa violencia, lo enfrentaba con ella sin mediaciones (no es ya un ejemplo de "buena voluntad que hace mala literatura"). El salto consistía en esa experiencia que se lograba hacer vivir al lector: los dedos presionando en el cuello.

En la presentación de su lectura, Fornet nos remitía a su experiencia de lector "puro", a la que había sido reducido por la bien atinada y calculada composición de la novela. Con dicha presentación nos encontramos en el centro mismo de los problemas y los temas estéticos, si es que queremos tomar este término en su sentido originario de aisthesis: de percepción y vivenciación. Lo que para Fornet hacía de Vargas Llosa "el mejor novelista joven de nuestra lengua" (Fornet 132) ${ }^{3}$ era que éste dejaba atrás una literatura de ideas y tesis mal plasmadas para optar por una literatura que apelaba sin filtro a las emociones y a la sensibilidad del lector. En ello se puede reconocer la modernidad que Fornet reclamaba entonces para esta novela: el hecho de construir de manera sostenida y redonda una experiencia estética. Pero ¿de qué estética se trataba? ¿De qué aisthesis? La respuesta a esta pregunta no solo es válida para esta novela. La obra entera de Vargas Llosa que le seguirá será un retrabajo, ampliación y variación -o repetición- de los patrones estéticos sentados con este inicio ${ }^{4}$.

${ }^{3}$ Entre tanto, como es de todos conocido, Vargas Llosa viene de recibir el Premio Nobel de literatura para el año 2010.

${ }^{4}$ Sobre las novelas que intentaron salirse de estos patrones estéticos con más o menos fortuna se puede ver mi libro Exilios y desexilios de la comicidad. Estudios sobre la novelística de Mario Vargas Llosa (Morales Saravia 2009). 
El rótulo "realismo crítico" empleado repetidas veces para describir esta obra esconde detrás, ciertamente, una estética determinada. El adjetivo "crítico" referido a la representación realista de un tema alude a dicha plasmación desde una perspectiva que toma distancia de lo narrado para enjuiciarlo. Esto implica necesariamente que lo narrado -la representación realista del asunto- lleva consigo un signo negativo. Esto adelanta uno de los aspectos decisivos de la estética vargasllosiana: ella es una estética de lo negativo o - para decirlo con el título del libro de Karl Rosenkranz (1853)- una "estética de lo feo"5. El mundo plasmado narrativamente es él mismo -así se lo pintael de lo bello negativo, es decir: el de lo feo. A esta estética -que uno podría llamar 'constructiva'- hay que sumarle, sin embargo, desde otra perspectiva, aquella a la que Fornet se refería cuando hablaba de su metamorfosis de lector "profesional" y "distanciado" en lector "puro". A la estética de lo negativo del mundo representado, construida por Vargas Llosa, se suma una aisthesis, una vivencia implícita a dicha construcción que la hace altamente "efectiva". Esta estética del efecto - Wirkungsästhetik-no es menos "negativa" y en ella tiene su sedimento buena parte del carácter "crítico" del realismo vargasllosiano. En lo que sigue quiero pasar revista a ambas perspectivas estéticas: la de lo contructivo y la del efecto vivencial negativos.

\section{ESTÉTICA NEGATIVA}

La representación de la "realidad", que el término realismo crítico presupone, ofrece, en el caso de La ciudad y los perros, un mundo narrativo localizado temporalmente en los años cincuenta del siglo XX -la mención de Manuel A. Odría trae a evocación su "ochenio" de gobierno-y espacialmente en Lima-la segunda palabra del título de la novela, "ciudad", alude a ella. Este mundo es construido 'negativamente' en todas sus instancias narrativas importantes: los objetos descritos, los personajes, las acciones de estos personajes -el plot-y los sentimientos y emociones que ellos experimentan.

${ }^{5}$ Erich Auerbach (514) se refería ya a la relación entre realismo y estética de lo feo en su conocido libro Mimesis. 


\subsection{EL PLOT: NOVELA POLICIAL}

Desde el punto de vista del plot en sentido estricto, La ciudad y los perros puede ser incluida dentro del género policial: en el centro de la peripecia se encuentra un crimen (cf. Schulz-Buschhaus 55-67). La representación de éste divide a la novela en dos partes. La primera muestra su prehistoria, la historia que lo explica y su realización. Los nódulos narrativos son: el robo del examen de Química, el error del ladrón, el descubrimiento del robo, el castigo de los imaginarias de turno hasta que aparezca el responsable, la delación que descubre al ladrón y causa su expulsión del colegio, la venganza de la delación y la muerte del delator. La segunda parte narra las investigaciones que se realizan para descubrir al asesino, la presumible falsedad de la detección y su final fracaso, pues el asesino no es castigado. A estas dos partes le sigue un epílogo que informa sobre el destino posterior de los principales personajes.

Este primer resumen del plot, que lo clasifica como policial, remite inmediatamente a uno de los tópicos modernos de una estética negativa: aquel que refiere la existencia del mal bajo el aspecto de la delincuencia o la criminalidad. Desde el punto de vista de las reglas sociales convenidas, tanto el robo como el asesinato son acciones que se encuentran fuera de la ley. Robar y asesinar van contra dicho acuerdo y colocan a sus ejecutantes en un espacio al margen de la sociedad. En términos estéticos, el género que se ocupa de este complejo temático es el de lo policial. En la novela que tratamos, estas acciones de robo y asesinato no tienen lugar fuera de la sociedad sino dentro de una de sus instituciones, dentro de una que tiene precisamente la función de educar a sus miembros en los convenios sociales. El escándalo referido que La ciudad y los perros ocasionó reside justamente en este hecho: pintar una institución educativa militar -el adjetivo 'militar' refuerza aquí el sentido de disciplina- que educa a sus pupilos para lo asocial.

Clasificar, pues, desde el punto de vista del plot, esta novela como policial permite llegar a una segunda constatación. El género de la novela policial apela siempre a una estética del mal y la pinta para, luego de realizada la detección, volver a instaurar, al final, el orden del bien. El escándalo que este texto también significó tiene que ver con el hecho de que en la novela las fuerzas sociales encargadas de restablecer ese orden del bien, es decir, de realizar correctamente la detección, localizar al culpable y hacerle pagar sus culpas, no asumen esta función. En la novela, las autoridades educativas militares prefieren no reconocer que se trata de un crimen, dan una versión 
falsa de éste como accidente, dejando así al asesino libre y sin culpas. A la elección de la estética negativa del mal que el género policial prescribe, se suma otra elección que desarticula la moraleja final estructuradora del género: la sociedad deja en su seno lo asocial y lo muestra, dentro de ella, en su impunidad. El orden del bien -el de los acuerdos sociales, el de las leyes- no opera verdaderamente.

\subsection{LOS PERSONAJES: BILDUNGSROMAN}

[1] Esto que se constata desde el dominio del plot y su referencia al género policial puede ser constatado también desde la consideración de los personajes de esta novela. La galería que ellos configuran puede ser dividida según sus edades: por una parte, los jóvenes del instituto educacional y, por otro, los adultos (militares o civiles); los cadetes, por un lado, y los oficiales, empleados y padres de los jóvenes, por otro. En todos los casos - menores o adultos- no solo aparece quebrantado el mundo del orden sino que los valores que allí rigen son falsos.

Los cadetes del "círculo" no son solo presentados desde sus apodos que los animalizan (Jaguar, Boa), sino desde sus acciones y comportamientos que son fracamente agresivos, crueles, finalmente, delictivos o mafiosos (el robo de prendas de vestir, de exámenes; el abuso de poder o influencias; el asesinato). Los cadetes obedecen, en el primer año, a la denominación de "perros" y son ultrajados, violentados e, incluso, violados, por los cadetes de años superiores. El orden y la disciplina reinan solo para afuera; en el mundo de los cadetes se está expuesto a la permanente agresión y hay que prepararse y estar preparado para defenderse. La ciudad y los perros puede ser considerada, desde la perspectiva de los personajes que son cadetes, como una antinovela de educación, donde el proceso de maduración conduce a aprender a ejercitarse en el dominio del mal. La razón de ser de Ricardo Arana -el personaje que es asesinado- en la novela debe ser vista en este contexto. Incapaz de poder moverse en el código de la violencia-como lo hace Alberto, el otro personaje principal que, sin pertenecer al "círculo", logra defenderse exitosamente de él-, Arana sucumbe ante esta dinámica "asocial", no logra (porque no cree en él) realizar el aprendizaje en lo negativo, es considerado traidor y ajusticiado por uno de los miembros del "círculo".

La posibilidad de atenerse a un orden que no sea ése de lo asocial y que prescinda de los valores de la violencia debería estar representada por el mundo de los adultos. Ella explica la razón de existencia del teniente Gamboa, 
el personaje que encarna en la novela los valores positivos. Respetado -y temido debido a su disciplina- por los cadetes, apreciado por los oficiales, Gamboa sucumbe también frente a la dinámica "asocial" en la que se halla inmerso, pues descubre demasiado tarde que las reglas que rigen el mundo (de los adultos) no tienen nada que ver con el mundo del orden que él cree representar. Informado del comportamiento "mafioso" y "delictivo" -de los valores que rigen el mundo de los jóvenes- se propone restituir el orden fracturado, asumir la detección del crimen cometido y hacer pagar sus culpas al asesino según lo prescribe la ley. Aquí coinciden el fracaso final del plot policial que no logra restituir el orden con la imposibilidad de revertir a términos positivos el plot implícito de la novela de educación. Gamboa descubre que ese mundo de adultos al cual pertenece está hecho también de mentira, violaciones al orden, abuso de poderes e influencias, y que no funciona de otra manera que como el mundo de los cadetes: como un "anti orden". Gamboa no está dispuesto ejercerse en el dominio del mal; por ello, como el cadete Arana que fracasa y muere, él ve morir también sus aspiraciones profesionales dentro del ejército al ser enviado a ese puesto de Juliaca que equivale no solo a una medida disciplinaria y a un castigo, sino a un verdadero envío al exilio.

Otra posibilidad de atenerse a un orden debería ser ofrecida por el mundo de los adultos, por el ámbito de los padres. Pero ni para Arana ni para Alberto representan sus mayores un modelo o una salida. El padre de Arana ha vuelto a vivir con su madre y está convencido de la necesidad de que su hijo sea educado dentro de los códigos de la violencia masculina. Arana accede a ingresar al colegio militar y a someterse a dicho aprendizaje porque prefiere sufrir una violencia que es ajena a la del padre. Ha comprendido que al regresar a vivir a Lima junto con su padre ha perdido su mundo infantil, su niñez en Chiclayo y, con ello, a su madre, la figura protectora frente al mundo. En el caso de Alberto, sus padres viven separados: las aventuras eróticas del esposo le resultan intolerables a la esposa y madre que se sume en el rol de víctima. Alberto no quiere oír más las quejas de su madre y el comportamiento libertino del padre lo impresiona.

También los otros personajes adultos de la novela están pintados de manera negativa: el hermano de Jaguar es un ladrón que está en la cárcel; la esposa de su tío lo seduce, cuando Jaguar va a vivir con ellos, y hace que éste opte por entrar al colegio militar como una forma de escapar de la amenaza que ella representa. En términos no menos negativos es presentada también la tía con la que vive Teresa, a quien no le interesa sino que su sobrina pesque 
un buen partido y pueda sacarla de la pobreza en la que se encuentran: poco menos que se la ofrece a Alberto cuando éste va a llevarle el mensaje de Arana a Teresa.

[II] No solo desde los valores negativos implícitos en sus acciones, sino también desde la descripción del aspecto físico de los personajes se recurre a los parámetros de una estética de lo feo. El caso más patente lo ofrece el propietario del quiosco que se encuentra dentro del colegio, lugar donde los cadetes van a tomar bebidas gaseosas, fumar, beber alcohol o realizar prácticas eróticas extrañas. Paulino, el propietario del quiosco, al que se designa como "injerto", es descrito en los siguientes términos:

ojos rasgados de japonés, ancha jeta de negro, pómulos y mentón cobrizos de indio, pelos lacios (La ciudad y los perros 142$)^{6}$.

La tía de Teresa es presentada en términos no muy distintos cuando Alberto la ve por primera vez: "un rostro grasiento" (La ciudad y los perros 121) que le da "una mano gorda y fláccida, sudada: un molusco" (La ciudad y los perros 121). La madre de Jaguar es percibida por él de la siguiente manera: "[...] veía su camisa llena de agujeros y remiendos, su cuello que hervía de arrugas, su cabeza greñuda" (La ciudad y los perros 381). La descripción del rostro de Boa reitera el tópico estético de lo deforme, desproporcionado y disarmónico:

un cuerpo y una voz desmesurados, un plumero de pelos grasientos que corona una cabeza prominente, un rostro diminuto de ojos hundidos (La ciudad y los perros 15).

La representación de Jaguar juega, de manera reiterada, con el tópico estético negativo de lo demoníaco: "El diablo debe tener la cara del Jaguar, su misma risa y además los cachos puntiagudos" (La ciudad y los perros, 196), piensa Boa repetidas veces. A esta galería de retratos "expresionistas" se viene a sumar la descripción del teniente Remigio Huarina que agrega a los registros estéticos negativos que él también representa ("parece más frágil y pequeño [...] el hocico, los ojos fruncidos y sin vida de batracio, el rostro redondo contraído en un gesto" (La ciudad y los perros 26), aquél de lo ridículo:

6 Cito de la edición definitiva de La ciudad y los perros (1999) en su sexta edición de 2003. 
Pequeño, enclenque, sus voces de mando inspiraban risa, sus cóleras no asustaban a nadie, los suboficiales le entregaban los partes sin cuadrarse y lo miraban con desprecio (La ciudad y los perros 165).

[III] A los retratos de los personajes y a la construcción negativa del plot-el del crimen- hay que añadir la presentación, también negativa, de acciones concretas de otros tantos protagonistas. Salvo el caso de los escasos personajes -fundamentalmente Teresa- que configuran y representan el valor positivo en la novela, y dejando de lado a Jaguar y Cava (portadores del plot policial) y a Arana y Gamboa (portadores del plot de la anti novela de educación), todos los demás roles aparecen ligados a acciones que son añadidos, desarrollos, variaciones de la estética de lo bello negativo: de la estética de lo feo.

Boa es, en este sentido, un personaje que recibe bastante espacio de tratamiento. Retratado en la novela desde el flujo de su consciencia, esta presentación lo muestra en un diálogo fingido con la Malpapeada, la perra que lo acompaña a todas partes y cuyo nombre da ya todas las restas efectuadas a su posible representación positiva. Sobre el tópico del perro como fiel amigo del hombre se construye en la novela una relación con este animal que alcanza niveles espantosos de representación. A la idea de fidelidad retomada aquí se le añade un matiz emotivo inesperado al cambiarle al animal de sexo y convertirla en perra, con lo que a lo emotivo de la relación hombre-perro se le otorga tanto un nuevo nivel sentimental como uno erótico. El nuevo nivel sentimental introducido humaniza a la perrra que resulta ser así la confidente del personaje, ya que es a ella a la que se dirige para contarle lo que siente y piensa sobre los acontecimientos principales (el robo y el asesinato). Esta humanización del animal no se realiza, sin embargo, bajo signos positivos, ya que la descripción de la perra muestra una deficiencia física -su nombre de "mal alimentada"- que por lo demás, también toca -por un proceso de identificación y por un proceso de sustitución-al propio personaje. El mismo Boa describe las crueles acciones del "círculo" para curarla de la sarna con ají que ocasiona que pierda toda la pelambre. Pronto él le toma cariño y lo dice: "le descubrí el gusto" (La ciudad y los perros 250). Un nivel erótico se sobrepone a la humanización del animal. Boa la convierte en su "pareja" erótica y confiesa que el animal es "igualito que las mujeres" (La ciudad y los perros 47). La novela acentúa de manera reiterada la relación erótica del personaje con la perra y esto con la repetida muletilla que emplea Boa en los diálogos -fingidos- con el animal: "Quieta, Malpapeada, estoy sintiendo tus dientes" (La ciudad y los perros 82). Pero con la introducción del nivel 
erótico en el tópico de "el perro fiel amigo del hombre" se animaliza al personaje: se lo rebaja a una condición que está por debajo de lo humano. La historia de Boa y la Malpapeada enfatiza, por lo demás, no solo el proceso de "animalización" de los personajes realizado a través de sus apodos, sino también sirve de amplificatio al tópico de las prácticas de los cadetes del "círculo" que usan sexualmente de las gallinas: “¿Nos tiramos la negra o la amarilla?" (La ciudad y los perros 44 ).

Paulino, el propietario del quiosco, es presentado también, desde sus acciones, bajo este aspecto. Alberto menciona varias veces en la novela lo que los cadetes van a hacer frecuentemente donde Paulino:

[...] saldremos del comedor y entraremos a las cuadras y alguien gritará un concurso y alguien dirá ya estuvimos donde el injerto y gano el Cava [...] (La ciudad y los perros 155) ${ }^{7}$.

La cita se refiere a los concursos de masturbación que Paulino organiza entre los cadetes (y que aprovecha para tocar y fellar a alguno de ellos), ofreciéndole al ganador en rapidez un premio en dinero.

Este registro de lo sexualmente chocante es representado también con las actividades que le han valido al personaje Alberto el nombre de "poeta". Éste escribe novelitas pornográficas que se regodean en lo erótico desde el lado más bajo, vulgar y chato de lo obsceno -lo obsceno es uno de los parámetros de una estética negativa:

Tenía las piernas gordas, blancas y sin pelos. Eran ricas y daban ganas de morderlas [...]; la mujer gemía, se jalaba los pelos, decía 'basta, basta', pero el hombre no la soltaba [...]" (La ciudad y los perros 172).

Es cierto que las autoridades del colegio se aprovechan al descubrir esta actividad para chantajear a Alberto y hacerlo que desista de su acusación de asesinato al Jaguar, pero ello no quita verdad a las frases del director que enfatiza precisamente lo negativo que se esconde tras la escritura de estos breves textos pornográficos:

${ }^{7}$ Otros pasajes se encuentran en La ciudad y los perros 158 y 163. 
Hay que tener un espíritu extraviado, pervertido, para dedicarse a escribir semejantes cosas. Hay que ser una escoria. Estos papeles deshonran al colegio, nos deshonran a todos (La ciudad y los perros 400).

Las palabras empleadas en la cita - perversión, extravío, escoria y deshonrarefuerzan el registro estético ya aludido y lo amplian. Pero que las novelitas sirvan de mecanismo de chantaje a las autoridades escolares para encubrir un crimen es un hecho que reduplica esa negatividad de la representación que toca ahora ya no solo al mundo de los jóvenes sino al de los adultos: no solo al de los educandos sino al de los educadores.

\subsection{El MUNDO DE LOS OBJETOS}

De manera equivalente a la construccion estética negativa del plot y de los personajes, que es un retrabajo irónico de la trama de la Bildungsroman, se da también la construcción del mundo objetual representado. El epígrafe que encabeza el epílogo de la novela, tomado de un poema de Carlos Germán Belli, puede ser entendido como resumen de este aspecto: “... en cada linaje el deterioro ejerce su dominio" (La ciudad y los perros 449).

Los edificios descritos, en especial, las instalaciones del colegio muestran este deterioro. El suelo está sucio (La ciudad y los perros 15), los vidrios de las ventanas, rotos (La ciudad y los perros 15); el estadio "languidece" ( La ciudad y los perros 27); la pista de atletismo está cubierta de baches ( $L a$ ciudad y los perros 27); las maderas de las tribunas se encuentran averiadas por la humedad (La ciudad y los perros 27]); el aula se presenta descolorida y manchada por la humedad (La ciudad y los perros 60); los baños son reductos sombríos con tablas agujereadas y musgosas (La ciudad y los perros 115); las paredes tienen "llagas grises" (La ciudad y los perros 243).

El mismo tratamiento descriptivo lo recibe el mobiliario. Las literas están oxidadas y chirrían (La ciudad y los perros 52); las sillas no tiene espaldares (La ciudad y los perros 115); las mesas están mugrientas. Y cuando este mobiliario no muestra deterioro, muestra sí rasgos malignos y agresivos como en la descripción del sillón de la oficina de los superiores que tiene extremidades de animal con plantas chatas y garras carniceras (La ciudad y los perros 399).

También los vestidos de algunos personajes -o ellos mismos-son descritos en estos mismos términos: la madre de Alberto tiene sobre la falda un delantal ajado (La ciudad y los perros 106); la tía de Teresa es gorda, sebosa (La ciudad 
y los perros 108), tiene los zapatos gastados (La ciudad y los perros 111) y un rostro grasiento; el padre de Arana muestra una barba rala, el cuello de su camisa presenta arrugas y manchas y la corbata, corrida, tiene además un nudo ridículo (La ciudad y los perros 251).

\subsection{LAS VIVENCIAS DE LOS PERSONAJES: EMOCIONES Y SENSACIONES}

En el mismo sentido tiene que ser vista la descripción que la novela trae de las emociones de los personajes, la descripción del impacto que este mundo, así pintado como deficiente, degradado, vil, obsceno y animalizado, produce en ellos. Pues la novela La ciudad y los perros no solo pinta este mundo sino también su forma de ser vivenciado, vinculando con ello la estética de lo feo, desde el punto de vista de la construcción del mundo representado, con la estética del efecto que él produce en los personajes.

Ya su incipit no hace otra cosa sino mostrar estas emociones mucho antes de que el lector sepa bien de qué trata la acción de la novela. Su tercera frase da ese temple emocional: "[...] el peligro había desaparecido para todos, salvo para Porfirio Cava" (La ciudad y los perros 15). Unas frases más abajo se lo lexicaliza claramente: "[...] era el miedo lo que erizaba su piel" (La ciudad y los perros 15). La palabra se vuelve a repetir unos renglones más abajo en la pregunta que le hace Jaguar: “- ¿Tienes miedo?" (La ciudad y los perros 17) y se vuelve a repetir cuando el narrador describe, inmediatamente, lo que Cava piensa: "Advirtió que el miedo lo paralizaría si no actuaba" (La ciudad y los perros 17). Y renglones más abajo vuelve a aparecer: "Un movimiento próximo e inesperado devolvió a su cuerpo, como un puñetazo, el miedo que empezaba a vencer" (La ciudad y los perros 18). Y una vez más todavía ("su respiración entrecortada por el miedo", La ciudad y los perros 19) antes de que se mencione el efecto de ese miedo en el personaje luego de haber robado el examen de Química: “- Serrano cobarde [...] Te has orinado de miedo. Mírate los pantalones" (La ciudad y los perros 21).

A lo largo de toda la novela, los personajes no sienten fundamentalmente sino miedo, miedo en todas sus variantes. Unas veces nombra ese miedo la palabra 'ansiedad' (La ciudad y los perros 18), como cuando Arana está por ver de nuevo a su padre y el efecto que esto le causa es "una ansiedad feroz" ( La ciudad y los perros 21); otras veces lo expresa la palabra 'angustia' ( $L a$ ciudad y los perros 22) o la palabra 'terror' (La ciudad y los perros 59-60); mayormente se traduce esta emoción negativa en su efecto: 
[...] su corazón late alocado, siente pánico (La ciudad y los perros 25). [...] su corazón dio un vuelco (La ciudad y los perros 102 y también 255).

[...] siente su corazón lleno de urgencia (La ciudad y los perros 183).

[...] su corazón se detuvo (La ciudad y los perros 209).

[...] el rostro aparece desfigurado por el miedo (La ciudad y los perros 68).

El miedo es, sobre todo, la vivencia primaria de los jóvenes cadetes, aunque Boa hable una vez de que los oficiales sienten miedo también (La ciudady los perros 99).

A la mención frecuente de la vivencia del miedo hay que sumar la reitereada mención de otras vivencias negativas. Por ejemplo, la vivencia del vértigo o falta de orientación (La ciudad y los perros 69 y 104), pero también la del dolor (La ciudad y los perros 106, 262 y 421) y la de las náuseas:

Poco después estallaban las arcadas y luego el vómito ruidoso ( $L a$ ciudad y los perros 69).

El Boa y el injerto me daban náuseas (La ciudad y los perros 162).

El agua de los caños del parque me hizo vomitar (La ciudad y los perros 417-418).

Sintió ganas de arrojar (La ciudad y los perros 421).

Otras emociones experimentadas por los personajes son las de sentir odio, ganas de vengar lo sufrido, decir blasfemias, maldecir (La ciudad y los perros 52), ejercer violencia ( La ciudad y los perros 54), maltratar, escupir y finamente deseos de castigar con la muerte, dentro de un extraño código de solidaridad.

No solo las emociones sino también la sensaciones que los personajes experimentan están presentadas de esta manera. Por una parte, éstos perciben el dominante color gris que cubre los edificios o la neblina y la fina garúa que hace la atmósfera y es parte de la utilería descriptiva de las escenas. Por otra parte, la descripción y percepción de los olores no es menos negativa. Todos son penetrantes y desagradables. Cito algunos ejemplos: 
[...] sus pies [de Jaguar] eran grandes y lechosos, de uñas largas y sucias, olían mal (La ciudad y los perros 20).

Los baños están vacíos, y uno de ellos apesta (La ciudad y los perros 29-30).

[...] y el cuarto se llenaba de olor a cebollas y ajos (La ciudad y los perros 81 ).

[...] un olor casi invisible a chicharrones y a pisco, a butifarras y a transpiración, a cerveza y pies (La ciudad y los perros 132).

[...] dijo una voz envenenada de cebolla [...] (La ciudad y los perros 133).

[...] con aliento a alcohol (La ciudad y los perros 144).

También la representacion de los sabores agota este registro de lo estéticamente negativo. Las comidas son insípidas (La ciudad y los perros 107); las bebidas dan náuseas (La ciudad y los perros 417-418); el viento arrastra un sabor a pescado y sal (La ciudad y los perros 353) y, en la historia de la seducción de Jaguar por su tía, se lee que ella "metía su lengua hedionda hasta las amigdalas" (La ciudad y los perros 421).

\section{ESTÉTICA DEL EFECTO}

La descripción del mundo narrado descansa, pues, sobre un registro -llamémoslo así: "expresionista"- que agota las diferentes posibilidades representativas desde una perspectiva de una estética de lo feo. Este es el pilar sobre el que descansa el realismo crítico atribuido a la obra de Vargas Llosa. Pero este registro no muestra el elemento diferencial de La ciudad y los perros en su "modernidad" frente a la tradición novelística anterior, tal y cómo lo expresaba Fornet en su reseña. La separación de aguas que Fornet proponía, a partir de esta novela, no puede ser atribuida a este hecho, ya que la novelística anterior trabajaba también este registro estético negativo (piénsese en Arguedas y Alegría o en otros autores). Dicho de otra manera: lo que Fornet verbalizaba al hablar de haber sido transformado, por el tratamiento de la materia novelística, en un "lector puro" va más allá de los aspectos estéticos negativos de cómo se construye el mundo representado y tiene que ver con los mecanismos puestos a funcionar en la obra para hacer que el lector vivencie -como los personajes-inmediatamente ese mundo así descrito. Con ello se plantea la pregunta por el efecto estético producido por la novela. 
Un primer acercamiento a esta pregunta ha estado dado por la presentación de las emociones y sensaciones que los propios personajes experimentan. La ciudad y los perros ofrece no solo un registro muy amplio del mundo visto negativamente sino también de cómo éste obra negativamente sobre la sensibilidad de los personajes. Queda ahora por preguntar cómo ese efecto da el salto del orden de los personajes al orden del lector: cómo el lector llega a sentir lo mismo que los personajes y se convierte, en la terminología de Fornet, en un "lector puro". Una respuesta a esta pregunta puede ser hallada en la consideración de los procedimientos formales ("modernos") empleados, principalmente, en la consideración de la perspectiva multiple de la narración, es decir, en el análisis de los varios narradores.

\subsection{LAS MÚLTIPLES PERSPECTIVAS}

La ciudad y los perros está dividida en dos partes (cada una con ocho capítulos) y un epílogo. Los capítulos presentan, cada uno, entre 1 y 10 apartados. El I, 1, por ejemplo, consta de cinco apartados: I,1a y I,1c narran, desde una perspectiva omnisciente, los acontecimientos del robo del examen de Química; I,1b presenta desde una tercera persona lo que siente y piensa el personaje Arana; I,1d narra en tercera persona (pero dentro del mundo narrado: perspectiva homodiegética) la infancia y adolescencia de Alberto, y I,1e es la transcripción del monólogo interior del personaje Boa (o de su fingido diálogo con la Malpapeada, su perra). A partir del capítulo I,3 la novela incluye un apartado más que narra, en primera persona y de manera retrospectiva, la historia de la infancia y del amor por Teresa de un personaje que, recién bastante avanzada la lectura, el lector identifica con el Jaguar.

Ordenada la novela según los apartados referidos a determinados personajes resultaría el siguiente esquema según la materia y, sobre todo, sus diferentes narradores:

1) Tenemos un narrador omnisciente que presenta los acontecimientos del presente: se trata del plot policíaco, y cuyos apartados serían: 
I,1a I,2a I,4 a I,5d I,6a I,8 ///// II,1b II,2b II,3b II,4c II,5b II,6a II,7a II,8a ///// Ep. A

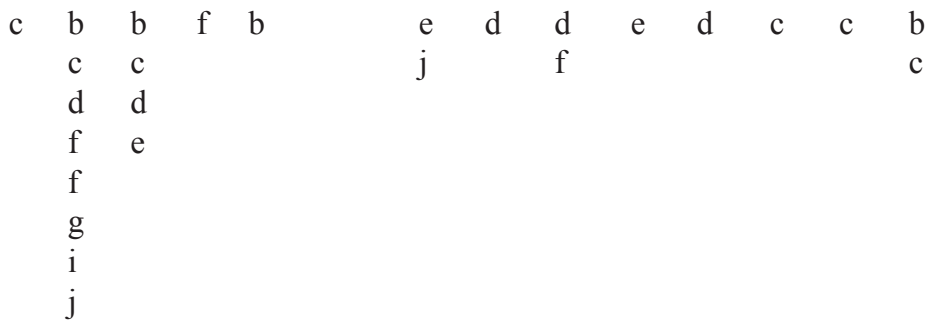

Importante de notar en esta distribución de los apartados es su fuerte presencia inicial en la primera parte de la novela: I, 1; I,2; I,6 y I,8 (capítulo central este último que solo consiste de un apartado y que narra los ejercicios militares de los cadetes y el crimen), mientras que esta presencia es más bien esporádica en la segunda parte, aumentando, sin embargo, a partir de II,5 para ser en II,8 la única perspectiva que domine la narración de los acontecimientos: en II,8a Jaguar es considerado traidor; en II,8b se presenta el fracaso de Gamboa frente a los superiores para realizar la detección del crimen; en II,8c la desilusión de Jaguar frente a los otros cadetes. Por lo demás, el epílogo narra, desde esta materia, la despedida de Gamboa y la confesión del crimen por parte del Jaguar. Este ordenamiento reforzaría la tesis de que se trata, para esta novela, del género policial, ya que él es la armazón de todo lo narrado y del presente de los hechos.

2) Dependiendo de este narrador se encuentra otro narrador omnisciente que presenta en tercera persona algunos eventos relacionados con el pasado inmediato de la historia de los cadetes, pasado que se retrotrae hasta la historia de su ingreso o a la descripción del colegio. Los apartados pertinentes son: I,2e (el bautizo de los cadetes y el círculo); I,4h (Vallano crea el mito de la Pies Dorados) y I,5b (descripción del quiosco "La Perlita").

Importante de señalar es que este narrador, a pesar de su empleo de la tercera persona, habla el lenguaje de los jóvenes cadetes y presupone que conoce la historia que se cuenta de primera fuente, es decir, que él se encuentra dentro del mundo narrado y muestra una cercanía con la perspectiva de los personajes.

3) Se halla un narrador en tercera persona que describe el pasado del personaje Arana-llamado "el esclavo"-y lo que él siente y piensa. Son estos apartados los que introducen el fracasado o no logrado plot de la novela de formación o Bildungsroman en la trama policíaca: 


\section{$\mathrm{I}, 1 \mathrm{~b} \mathrm{I}, 3 \mathrm{e} \mathrm{I}, 5 \mathrm{c} \mathrm{I}, 7 \mathrm{e} / / / / / \mathrm{II}, 1 \mathrm{f}$}

Estos apartados aparecen solo en la primera parte de la novela, mientras el personaje Arana vive todavía, y una sola vez en la segunda parte para acentuar el carácter crítico de esta materia, pues en II,1f se narra la decisión de Arana de entrar al colegio Leoncio Prado para huir así de su autoritario padre y de la por él sentida "traición" que su madre le inflige al regresar a vivir con el padre a Lima, lo cual resulta, después de haber narrado su muerte en I,8 una decisión fatalmente irónica.

4) Hay un narrador en tercera persona que presenta el pasado del personaje Alberto en su barrio de Miraflores, narrador que describe no solo las calles sino también los amigos, especialmente el frustado enamoramiento de Alberto, el desplante que le hace Helena y que motiva su ingreso al colegio militar. Es este mismo narrador el que en el epílogo termina de contar la historia de Alberto que ha regresado a su barrio después de concluir el colegio. Los apartados son:

\section{I,1d I,3c I,5e I,7c ///// II,1h //// Ep. B}

5) Tenemos el monólogo interior del personaje Boa, monólogo desarrollado bajo la forma de un fingido diálogo del personaje con la perra Malpapeada. La función de estos apartados es la de reconstruir la historia inmediata vivenciada por los cadetes así como la de dar el temple anímico con que se los vive. Los apartados son:

$$
\begin{array}{ccc}
\text { I,1e I,3b I,7b ///// II, 1a II,3a II,4a II,5a } \\
\text { d d } & \text { d e } \\
& \text { g } \\
& \text { i }
\end{array}
$$

Llama la atención que estos apartados se encuentren desde el principio de la novela, pero que ellos hayan sido acumulados, sobre todo en el primer capítulo de la segunda parte para acentuar la perspectiva interna de considerar los acontecimientos principales: robo y muerte. A la presencia de estos apartados corresponde la ausencia de apartados que narran los hechos desde una perspectiva exterior y omnisciente. 
6) Existe un narrador en primera persona que cuenta su pasado antes del ingreso al colegio militar y que narra su vida después de haber salido de dicho colegio. Se trata del personaje Jaguar que presenta su historia anterior a su vida de colegial desde el recuerdo. La narración es cronológica y el punto temporal de su realización resulta impreciso, probablemente haya que colocar ese punto en el futuro de los hechos principales, es decir, desde una especie de epílogo a los hechos. Este narrador supone un interlocutor, ya que la narración finge las reglas de la confesión oral o del relato en presencia de otra persona que lo escucha. Los apartados son:

$$
\text { I,3a I,5a I,7a // II,1c II,2a II,3c II,4b II,5c II,6b II,7b // Ep C }
$$

c

d

Importante de notar es que se inica recién en el capítulo 3 de la primera parte y que su mayor espacio de desarrollo se encuentra en la segunda parte y que la misma novela concluye con este narrador y con esta materia. Estos apartados traen un plot de novela de formación o Bildungsroman y presentan el proceso "exitoso" del desarrollo del personaje Jaguar, proceso que debe ser puesto en relación con el otro plot policial de la novela, lo que hace saltar la posición social crítica de Vargas Llosa y su ironía, ya que es el asesino -impune-el que al final alcanza esa felicidad hecha de rebeliones y compromisos que el esquema de la Bildungsroman implica.

\subsection{LOS NARRADORES}

La forma de composición de la novela, que acabo de presentar, explica uno de los elementos que contribuyen a crear ese fuerte efecto en el lector del que hablaba Fornet. La pluralidad de perspectivas ofrece una percepción matizada de los acontecimientos. Sin embargo, en todos los casos, esos matices no resultan estar en una discrepancia tan grande unos de otros, ya que ellos coinciden en presentar las vivencias que estos acontecimientos ocasionan dentro de una estética de la negatividad. No solamente la pluralidad de perspectiva opera para crear el efecto, sino el tratamiento efectista de los narradores.

Desde el punto de vista de la composición existen, por lo menos, seis tipos de apartados diferenciables entre sí. Primero, los que narran el plot policial, los que recuerdan el pasado inmediato de los personajes, los que presentan las vivencias de Arana y los que narran la infancia de Alberto antes de ingresar al colegio militar: todos estos apartados presentan un narrador en tercera persona. Luego están, además, los apartados del diálogo fingido o monólogo 
y los apartados que narran la historia anterior del Jaguar: ambos tipos de apartados emplean, por su parte, la primera persona. Esta partición en dos narradores (el de primera y el de tercera persona) ofrece algunas variaciones de importancia que es necesario explicar para describir ese efecto mencionado que convierte a un lector crítico y distanciado en un "puro lector", es decir, en un lector que es sumergido en los acontecimientos para que los viva.

\subsubsection{El narrador en tercera persona}

El primer aspecto que debe ser visto es el de la configuración de la instancia narrativa en tercera persona. Es el narrador representante de la omniscencia: está informado de los acontecimientos y su lugar se encuentra en un futuro, en un tiempo posterior a los hechos narrados que apenas resulta fijable. Esta tercera persona no tiene nombre, no está personalizada. Sin embargo, repetidas indicaciones en su presencia omnisciente llevan a tener que situarlo, no en un lugar neutro y abstracto, sino por el contrario muy cerca de los hechos narrados. Esta cercanía se muestra en su forma de emplear apelativos para nombrar a los personajes o en el alarde de conocimientos e información que son solo posibles de poseer a un insider. Quiero mostrar este hecho ofreciendo algunos ejemplos de los distintos apartados aislados más arriba, tomándolos del capítulo primero. Elijo I,1a y I,1c que pertenecen a los apartados que narran el plot policial. En el incipit de I,1 se lee:

Los rostros se suavizaron en el resplandor vacilante que el globo de luz difundía por el recinto, a través de escasas partículas limpias de vidrio: el peligro había desaparecido para todos, salvo para Porfirio Cava. Los dados estaban quietos, marcaban tres y uno, su blancura contrastaba con el suelo sucio (La ciudad y los perros 15).

Aquí tenemos a todas luces la presentación de los rasgos de la omniscencia y del tiempo que la caracteriza: el narrador presenta la acción desde fuera y desde esa distancia puede él percibir la diferencia entre la blancura de los dados y la suciedad del piso. Esta distancia es marcada también al ser mencionado el personaje por su nombre y apellido: Porfirio Cava. Esta omnisciencia se reafirma en el párrafo que le sigue:

Cava sintió frío. Los baños estaban al fondo de las cuadras, separados de ellas por una delgada puerta de madera, y no tenían ventanas ( $L a$ ciudad y los perros 15). 
Esta distancia parece romperse por un momento cuando introduce una comparación que implica de alguna manera un saber de insider:

En los años anteriores el invierno solo llegaba al dormitorio de los cadetes, colándose por los vidrios rotos y las vendijas; pero este año era agresivo [...] (La ciudad y los perros 15).

El uso de la oposición "años anteriores" / "este año" parece romper la distancia temporal narrativa, aunque el empleo del denominativo neutro y general "los cadetes" reintroduzca esa distancia. Un cambio en las funciones denominativas rompe de nuevo, ahora totalmente, esa distancia cuando el narrador omnisciente emplea el lenguaje de sus personajes y se sitúa en su nivel: "El Jaguar se había vuelto a mirarlo" (La ciudad y los perros 15). Que el narrador omnisciente, hasta ahora más o menos neutro y distante, nombre a un cadete por su apodo -como lo hacen los cadetes-introduce al narrador súbitamente en el interior de la acción: la perspectiva externa se convierte en perspectiva interna. Con el uso de este mecanismo, la novela logra obrar en el lector una cercanía a los hechos narrados (la cercanía de un narrador -omnisciente- que pasa de ser heterodiegético a configurarse como homodiegético) $)^{8}$.

En I,1c pueden verse con mayor claridad estos procedimientos de crear cercanía a los acontecimientos narrados. Allí se presenta la guardia nocturna de los imaginarias de esa noche en que el cadete Porfirio Cava roba el examen de Química. Alberto necesita dinero y piensa en cómo conseguirlo, merodea por los patios del colegio hasta que se encuentra con Ricardo Arana, uno de los dos cadetes que está de imaginaria y que por ello verá a Cava robar el examen y podrá así posteriormente denunciarlo (con lo que aparece el motivo del crimen). El narrador omnisciente presenta entre comillas (así queda claro su rol omnisciente) lo que el personaje Alberto piensa:

"Podría ir y decirle [a mi padre] dame veinte soles y ya veo, se le llenarían los ojos de lágrimas y me daría cuarenta o cincuenta [...]" (La ciudad y los perros 23).

Luego el narrador describe el físico y la vestimenta de Alberto:

${ }^{8}$ Birger Angvik (91) habla, apoyándose en los trabajos de Ellisiv Stehen de "un tipo de narración que se caracteriza por ser "formalmente autoral pero con color personal" ". 
Bajo la bufanda de lana que le regaló su madre hace meses, los labios de Alberto se mueven sin ruido. El sacón y la cristina que lleva hundida hasta las orejas lo defienden contra el frío (La ciudad y los perros 23).

Luego pasa a presentar lo que el personaje percibe sin indicaciones que marquen su funciones de narrador, saltando con ello de la distancia omnisciente a la inmediatez del personaje:

Desde ahí va entre los barrotes, como el lomo de una cebra, la carretera asfaltada que serpentea al pie de la baranda y el borde de los acantilados, escucha el rumor del mar y, si la neblina no es espesa, distingue a lo lejos, igual a una lanza iluminada, el malecón del balneario de La Punta penetrando en el mar como un rompeolas y, al otro extremo, cerrando la bahía invisible, el resplandor en abanico de Miraflores, su barrio (La ciudad y los perros 24).

El procedimiento que hace hablar al narrador desde el personaje rompe la distancia omnisciente y crea cercanía: el narrador se convierte en una especie de "reflector" de lo que el personaje experimenta o percibe.

Pero esta cercanía también se crea en I,1c, identificando más directamente al narrador con el mundo de las acciones de la novela. Luego de haber revisado los patios y los baños, el personaje Alberto se topa con el cadete Ricardo Arna; la presentación de éste por el narrador omnisciente acontece en el argot de los cadetes y utilizando el apodo que tiene:

Atravesado en la columna de la luz, surge un rostro lánguido, una piel suave y lampiña, unos ojos entrecerrados que miran con timidez [...]. el Esclavo levanta una mano para protegerse de la luz (La ciudad y los perros 31).

El narrador se pone en el nivel de los personajes y es percibido ocupando un lugar dentro del mundo de ellos.

Este mismo procedimiento puede ser verificado más extensamente en I, $1 \mathrm{~d}$, donde se relata la infancia del personaje Alberto en el barrio de Miraflores. La inicial descripción del barrio pasa pronto - por los pormenores y detalles que ofrece- de ser la de un narrador omnisciente a ser la de un narrador (siempre en tercera persona) que dispone de datos, informaciones, vivencias que solo puede tener un insider, una persona que ha vivido en dicho barrio. También el empleo de designaciones que correspondería usar a personajes o a habitantes de ese barrio crea cercanía al mundo representado: 
Cuando se formó un equipo de fulbito para intervenir en el campeonato anual del Club Terrazas, los muchachos se presentaron con el nombre de Barrio Alegre. Pero, una vez terminado el campeonato, el nombre cayó en desuso. Además, los cronistas policiales designaban con el nombre de Barrio Alegre al jirón Huatica de La Victoria, la calle de las putas, lo que constituía una semejanza embarazosa. Por eso, los muchachos se limitan a hablar del barrio (La ciudad y los perros 40; cursivas mías).

En los otros apartados, aquellos referidos al personaje Arana que también traen un narrador omnisciente, pueden constatarse procedimientos similares en lo que toca a la omnisciencia de la tercera persona. Estos - cinco-apartados (I,1b; I,3e; I,5c; I,7e y II,1f) se inician de la misma manera con una frase que tiene una función anafórica que opera, de apartado a apartado, a manera de una letanía (pero también dentro de cada apartado) y que funge de principio constructivo del mismo. El narrador en tercera persona relata aquí los sucesos más importante en la vida de Arana antes de que entre en el colegio militar: su regreso de Chiclayo donde vivía con su madre en un mundo infantil feliz y el primer encuentro con el padre (I,1b); los primeros días en Lima y las peleas violentas del padre con la madre (I,3e); la estricta disciplina diaria a que lo somete el padre que quiere educarlo como un "hombre" (I,5c); el descubrimiento de que su madre está del lado del padre y la desilusión que esto le produce $(\mathrm{I}, 7 \mathrm{e})$ y su decisión de entrar como interno al colegio Leoncio Prado para salir de su casa (II,1f). En todos estos casos, el narrador inicia cada apartado con una frase semejante que es una especie de oxímoro que juega con los tópicos de recuerdo y olvido:

Ha olvidado la casa [...] donde vivió desde la noche que llegó a Lima [...] (La ciudad y los perros 21).

Los días siguientes, monótonos y humillantes, también los ha olvidado (La ciudad y los perros 101).

Ha olvidado también que al día siguiente estuvo mucho tiempo con los ojos cerrados después de despertar (La ciudad y los perros 144).

Ha olvidado los hechos minúsculos, idénticos, que constituían su vida [...] (La ciudad y los perros 209).

Ha olvidado ese mediodía claro, sin llovizna y sin sol (La ciudad y los perros 254). 
El narrador recuerda lo que el personaje ha olvidado: éste es el contenido repetido que ofrecen estos apartados. Pero el narrador recuerda no desde su omnisciencia; él no expone los acontecimientos sino la percepción y la vivencia de ellos por el personaje y en una forma en que la narración propiamente dicha deja de serlo para convertirse en un discurso de los sentimientos del personaje. El narrador en tercera persona presenta la perspectiva interior emotiva del personaje y retrocede frecuentemente para, fungiendo de "reflector", hacer aparecer directamente a Arana 9 :

Algunas mañanas, salía a dar una vuelta. A las diez, la avenida Salaverry estaba solitaria, de cuando en cuando pasaba un ruidoso tranvía a medio llenar. Bajaba hasta la avenida Brasil y se detenía en la esquina. No cruzaba la ancha pista lustrosa, su madre se lo había prohibido. Contemplaba los automóviles que se perdían a lo lejos, en dirección al centro y evocaba la Plaza Bolognesi, al final de la avenida, tal como la veía cuando sus padres lo llevaban a pasear: bulliciosa, un hervidero de coches y tranvías, una muchedumbre en las veredas, las capotas de los automóviles semejantes a espejos que absorbían los letreros luminosos, rayas y letras de colores vivísimos e incomprensibles. Lima le daba miedo, era muy grande y uno podia perderse y no encontrar nunca su casa, la gente que iba por la calle era desconocida (La ciudad y los perros 211; cursivas mías).

A la descripción de las acciones del personaje sigue la visualización de lo que éste ve y percibe, y luego la traducción de esa visión en conceptos vivenciales que remiten a experiencias negativas. En este otro ejemplo, a la presentación omnisciente del narrador le sigue la pregunta que el personaje (no el narrador) hace:

El los observaba, muy serio y desconcertado: ¿por qué no podía ser como ellos, vivir sin preocupaciones, tener amigos, parientes solícitos? (La ciudad y los perros 255).

Lo que el personaje Arana percibe y siente en estos apartados es, pues, toda la paleta de emociones y experiencias que desembocan en la vivencia del miedo: en el primer apartado se lee sobre la frialdad, el lecho hostil, la soledad y la angustia; en el segundo, sobre la humillación; en el tercero, sobre el terror y, en

9 El término "reflector" procede de la tipología narrativa que hace Franz K. Stanzel. 
el cuarto, sobre el desánimo, la amargura y el rencor; finalmente en el quinto apartado se habla del temor al futuro. El hecho de que el narrador reitere, como principio constructivo de estos apartados, el olvido de estos hechos no hace sino reforzar lo que no se puede olvidar en el presente de las acciones que tienen lugar en el colegio Leoncio Prado relatadas en la novela. Su vida llena de estos elementos no lo pueden preparar para alcanzar la madurez, sino para terminar en la muerte como víctima injusta de un mundo despiadado.

\subsubsection{El monólogo}

Si el discurso omnisciente que presenta la vivencia de los personajes y el rol de "reflector" de la tercera persona narrativa tenían por meta romper la distancia entre la narración y lo narrado, la ruptura de tal distancia se realiza plenamente en los apartados dedicados al personaje Boa. Como el personaje Jaguar, el personaje Boa no es aludido en la novela sino por este apelativo; este hecho sitúa al narrador en el nivel de los personajes y lo introyecta -con él también al lector- en el mundo representado. El lector tiene inmediato acceso al mundo interior de los personajes. Lo que el personaje Boa siente y percibe y lo que él piensa sobre ello no está "filtrado" por un narrador en tercera persona (por supuesto sí por el autor), pues el personaje habla o piensa en primera persona. El monólogo interior del personaje Boa está trabajado mayormente (en los apartados I, 1e; II,3b y en II,4a) como un fingido diálogo con la perra Malpapeada, quien asume ahí el rol de confidente. Pero en estos monólogos de Boa hay una primera persona que reproduce, sin marcar a los hablantes, diálogos de cadetes involucrados en diferentes acciones del "círculo" (comercio sexual con gallinas, intento de violar a un cadete en una cuadra vecina, peleas con los cadetes del año superior, etc.). Este narrador en primera persona asume el rol de hacer hablar a los otros personajes en discurso directo. Simultaneidad de acciones narradas, perspectiva de los personajes, posición del narrador en primera persona frente a los hechos resultan ser aquí las características principales:

Cava nos dijo: detrás del galpón de los soldados hay gallinas. Mientes serrano, no es verdad. Juro que las he visto [...] ¿Y que pasa si el rulos se tira al muchacho? Lo mejor, dijo el Jaguar, es amarrarle las patas y el pico (La ciudad y los perros 44).

La apelación a la Malpapeada da, frecuentemente, empero, el orden del discurso a estos apartados: 
Pero mejor que la gallina y el enano, la del cine. Quieta Malpapeada, estoy sintiendo tus dientes (La ciudad y los perros 82).

Tienes una lengua caliente, Malpapeada, una lengua larga y quemante (La ciudad y los perros 347).

Estos apartados relatan -es su función- aquellos acontecimientos que repercuten fuertemente en la sensibilidad de los personajes y que las otras instancias narrativas presentes en la novela no pueden presentar. Junto a los acontecimientos que mencionan el ejercicio de la violencia están aquellos que describen el miedo que los cadetes experimentan, por ejemplo, en relación con el arresto de Cava y su expulsión del colegio, así como también en relación con la cólera que esto ocasiona y que lleva a Boa a golpear a la perra hasta lisiarla (II,1a/d/g/i). Boa piensa:

Tengo pena por la perra Malpapeada que anoche estuvo llora y llora [...] Varios se levantaron y vinieron a mi cama con los botines en la mano. No era cosa de machucarse con toda la sección ahora que estamos tan deprimidos (La ciudad y los perros 239).

La depresión mencionada en la cita es tema de otros dos apartados (II,3 a/e) que narran los sentimientos que ha causado en la sección, especialmente en Alberto, la muerte de Arana. El último monólogo presenta el miedo que sienten los cadetes cuando los oficiales registran los roperos y encuentran todo tipo de objetos prohibidos (II,5 a):

Después tocaron el pito para almorzar y creo que fue la primera vez desde que estoy en el colegio que no comí casi nada, la comida se me atragantaba en el cogote (La ciudad y los perros 374).

\subsubsection{La primera persona}

Como en los apartados dedicados al monólogo de Boa, también en los apartados que relatan la historia pasada de Jaguar se hace uso de una primera persona. Pero ésta cuenta allí los acontecimientos de su vida de forma cronológica. El rasgo dominante de esta narración es su fingido carácter oral: el dar la impresión de que el narrador está relatando los hechos de manera directa a un interlocutor no mencionado nunca por su nombre pero que se encuentra bastante cerca de la posición del lector en la medida en que él es el interpelado performativamene por el narrador. Este relato en primera persona se sitúa 
temporalmente después de los acontecimientos principales narrados en la novela y los presupone. La materia de este relato es la historia amorosa de Jaguar con Teresa desde que son niños. Interesante resulta anotar que el último apartado de la novela presenta a Jaguar, muchos meses después de haber salido del colegio y de estar trabajando en una agencia bancaria, contándole a un interlocutor cómo volvió a encontrarse con Teresa en la calle de casualidad y cómo al poco tiempo de este encuentro se casaron. Este último apartado de la novela está construido en forma de diálogo pero de tal manera que, a tramos, hace aparecer un narrador en tercera persona que funge de "reflector" de lo que el personaje ve en su recuerdo a la hora de relatar su reencuentro con Teresa. Que la situación comunicativa dialogal sea la de dos amigos -Jaguar y el flaco Higueras- que se vuelven a encontrar y que sentados y bebiendo en un bar conversan sobre su vida, ofrece tal vez una solución a la situación comunicativa de los acápites narrados en primera persona. Como en el último apartado de la novela, en los acápites en los que Jaguar narra la historia de su amor infantil a Teresa y de su iniciación en la vida delictiva por la influencia de algunos amigos, se trata de una narración con un interlocutor que solo escucha. Sin embargo una identificación entre ese interlocutor mudo y la figura de Higueras no puede ser propuesta ya que en tales acápites el "flaco Higueras" es personaje de la narración y no interlocutor:

Yo estaba en el Sáenz Peña y a la salida volvía a Bellavista caminando. A veces me encontraba con Higueras, un amigo de mi hermano [...] (La ciudad y los perros 80).

Sin embargo, los dos tiempos -el de los apartados en primera persona y el del último apartado de la novela en el epílogo-no pueden estar tan distantes uno de otro temporalmente (la presumible suposición de que el relato del amor infantil de Jaguar sea paralelo temporalemente al robo del examen por Cava $\mathrm{y}$ al asesinato de Arana resulta imposible por la distancia de tiempo marcada en la relación que se hace de estos acontecimientos, pero también porque el Jaguar del colegio no habla nunca de amor ni está dado a hacer confidencias).

\subsubsection{Los diálogos}

Esta cercanía creada frente al lector por los apartados en primera persona se transforma en inmediatez y presencia del lector en los acontecimientos mismos mediante el uso que hace la novela del diálogo: es el momento de mayor cercanía. El diálogo del último acápite de la novela instaura un nuevo 
presente: el presente después de todo lo acontecido en el Colegio Militar. Ciertamente que éste es reenviado al pasado por las marcas y anotaciones ocultas del narrador hechas en pretérito indefinido ("dijo Jaguar", "dijo el flaco"). Sin embargo, el hecho decisivo es que el diálogo se realice en tiempo presente y que por ello cree una actualidad, poniendo al lector en el rol de espectador "físico" de una especie de puesta en escena teatral. El empleo del diálogo en la novela es muy frecuente y cumple esta función de hacer inmediato y presente lo narrado. Hay apartados que no son sino diálogos entre los personajes, apenas acotados o presentados por un narrador en tercera persona. El diálogo sirve, por ejemplo en I,5f, para que Arana le cuente a Alberto que está enamorado de Teresa. El diálogo se emplea, pues, más frecuentemente en aquellos apartados en que se quiere acercar al lector a la forma de pensar, sentir y obrar de los personajes. Por citar otros ejemplos: en II,2b aparecen los oficiales en un diálogo hablando de cómo darán una versión del accidente (asesinato) de Arana; en II,6a se presenta el encuentro de Alberto con el coronel, director del Colegio, quien lo intimida y lo obliga a retirar la acusación de asesinato; en II,6c se trata de la disputa verbal entre Alberto y Jaguar en el calabozo en que Alberto lo acusa de ser el asesino de Arana; en II,8a se muestra la acusación de traición que los cadetes le hacen a Jaguar después de que los oficiales han revisado los roperos; en el epílogo se presenta, igualmente, el diálogo entre Gamboa y Jaguar, quien le confiesa haber matado a Arana cuando el caso ya no se puede volver a abrir. Sin embargo, el acápite que muestra de manera más clara la voluntad del autor de planear el efecto de lo narrado en el lector es el incipit de la novela: ahí se parte in medias res con un diálogo que sitúa al lector en medio de los hechos: la decisión tomada para el robo del examen de Química. No en los acontecimientos mediados por una perspectiva narrativa sino directamente en ellos. Así al lector se le resta, desde el principio y de manera repetida, mediaciones frente a la materia narrada y se lo convierte, para emplear de nuevo la expresión de Ambrosio Fornet, en un "puro lector".

Mi punto de partida había sido preguntar por los mecanismos que habían llevado precisamente al "lector" Fornet a abandonar su distancia crítica frente a la primera novela de Vargas Llosa y a convertirlo en un "lector puro". Detrás de este fenómeno veía Fornet el momento de "modernidad" de esta "nueva novela hispanoamericana" que Vargas Llosa representaba ejemplarmente. La pregunta era tanto por la materia tratada como por la forma cómo ella obraba sobre el lector. Si bien la materia elegida (la vida de los cadetes de un colegio militar, el asesinato de uno de ellos y la actitud de las autoridades 
de esconderlo) hablaba del "realismo crítico" por el que Vargas Llosa optaba desde su primera novela, nuestra pregunta era cómo este "realismo" operaba en el lector para causar el efecto "estético" descrito. La respuesta que hemos dado a esta pregunta ha seguido dos líneas de consideración. La segunda parte de este trabajo se ha ocupado de mostrar cómo debe ser entendido el adjetivo "crítico" referido al realismo en lo que él conlleva de representación negativa del mundo narrado. Esto ha mostrado uno de los aspectos decisivos de la estética vargasllosiana: el de ser ella una de lo bello negativo o "estética de lo feo". Esto tiene que ver no solo con los dos plot que se entrelazan en la construcción de la acción -el de lo policial y el de lo formativo- que son puestos en tela de juicio, sino también con la extensa y omniabarcante representación de un mundo deficiente, degradado, vil, obsceno, demoníaco y animalizado, en lo que se refiere a personajes y objetos. Pero lo que Fornet verbalizaba al hablar de haber sido transformado, por el tratamiento de la materia novelística, en un "lector puro", si bien partía de los aspectos estéticos negativos de cómo se construye el mundo representado, iba más allá de ellos y tenía que ver con los mecanismos puestos a funcionar en la obra para hacer que el lector vivenciara, como los personajes, "inmediatamente" ese mundo así descrito. Con ello se planteaba la pregunta por el efecto estético producido por la novela. La respuesta que la tercera parte de este trabajo ha dado a esta pregunta partía del análisis de lo vivido y vivenciado (a eso remite el término aisthesis) por los personajes -es el tema del omnipresente sentimiento de miedo y de las sensaciones de malestar, vértigo y náuseaspara luego ocuparse de los mecanismos -se trata de la forma cómo Vargas Llosa creaba cercanía a lo narrado mediante el uso de las perspectivas de la narración y sus diferentes narradores-que conducían al lector a hacerlo vivir y vivenciar "sin filtro" la extensa representación negativa del mundo narrado.

\section{BIBLIOGRAFÍA}

Agüero, Luis y Juan Larco. "Sobre La ciudad y los perros, de Mario Vargas Llosa". Casa de las Américas 30 (1965): 63-80.

Angvik, Birger. La narración como exorcismo. Mario Vargas Llosa (1963-2003). Lima: Fondo de Cultura Económica, 2004.

Auerbach, Erich. Mimesis. Dargestellte Wirklichkeit in der abendländlichen Literatur. Tübingen/Basel: Francke, 2001.

Bellini, Giuseppe. "Un patibolario elogio di Vargas Llosa”. Rassegna Iberistica 35 (1989): 17-28. 
Boldori, Rosa. "La ciudad y los perros, novela del determinismo ambiental”. Revista peruana de cultura 9-10 (1966): 92-113.

Fornet, Ambrosio. "La ciudad y los perros". Casa de las Américas 26 (1964): 129-132.

Hancock, Joel. “Animalization and Chiaroscuro Techniques: Descriptive Language in La ciudad $y$ los perros (The City and the Dogs)". Latin American Literary Review IV/7 (1975): 37-47.

Johnson, Philip."The Shadow of the City: Society and Disorder in La ciudad y los perros". The American Hispanist 1/ 6 (1976): 12-15.

Lastra, Pedro. "Un caso de elaboración narrativa de experiencias concretas en 'La ciudady los perros "'. Letras XXXVII/ 74-75 (1965): 173-178.

Magnarelli, Sharon. "The Time of the Hero: Liberty Enslaved". Latin American Literary Review IV/8 (1976): 35-45.

Magnarelli, Sharon. "La ciudad y los perros: Women and Language". Hispania 64/ 2 (1981): 215-225.

Magráns, Ramón. "Anti-Totalitarianism in Animal Farm and Time of the Hero". SELA XXVIII/ 4 (1985): 9-14.

McMurray, George R. "Form and Content Relationships in Vargas Llosa's 'La ciudad y los perros " ". Hispania 56/ 3 (1973): 579-586.

Morales Saravia, José (ed.). Das literarische Werk von Mario Vargas Llosa. Frankfurt am Main: Vervuert, 2000.

Exilio y desexilios de la comicidad. Estudios sobre la novelística de Mario Vargas Llosa. Lima: Editorial San Marcos, 2009.

Payne, Judith A. "Anima Rejection and Systematic Violence in La ciudad y los perros". Chasqui XX/1 (1991): 43-49.

Promis Ojeda, José. “Algunas notas a propósito de 'La ciudad y los perros' de Mario Vargas Llosa“. Signos 1/1. (1967): 63-69.

Rogmann, Horst. "Mario Vargas Llosa: Die Stadt und die Hunde". Die Neueren Sprachen 67, 10 (1968): 514-522.

Rosenkranz, Karl. Ästhetik des Häßlichen. 1853. Leipzig: Reclam, 1990.

Schulz-Buschhaus "Vargas Llosas Kriminalromane". José Morales Saravia (ed.). Das literarische Werk von Mario Vargas Llosa. Frankfurt am Main: Vervuert, 2000. 55-67.

Soubeyroux, Jacques. "Pour une étude de l'espace dans le roman. Propositions méthodologiques et application à La ciudad y los perros de Vargas Llosa". Imprévue 1 (1985): 37-55.

Standish, Peter. Vargas Llosa. “La ciudad y los perros”. London: Grant \& Cutler, 1982.

Stanzel, Franz K. Theorie des Erzählens. Göttingen: Vandehoeck \& Ruprecht, 2009.

Vargas Llosa, Mario. La ciudad y los perros. Madrid: Alfaguara, 2003.

"El país de las mil caras". Contra viento y marea, III (1964-1988). Barcelona: Seix Barral, 1990. 227-246. 